\title{
Role of m-Banking for Indian Rural Consumers, its Adaptation Strategies, and Challenges: Consumer Behavior Analysis
}

\author{
Shyam R. Sihare \\ Asstt. Professor, Department of Computer Science and Application,Dr. APJ Abdul Kalam Govt. College, \\ Silvassa, Dadra \& Nagar Haveli (UT)-396235, India \\ Email: shyams_sihare1979@rediffmail.com
}

Received: 19 May 2017; Accepted: 05 July 2017; Published: 08 November 2017

\begin{abstract}
An information technology is a part of modern society for completion of their daily schedule with sophisticated accuracy, effectiveness, efficiency and maintaining transparency. However, modern technology penetration into root level in modern Indian society is not in an appreciable in particular of rural India. Among different applications of wireless communication means a significant application is $\mathrm{m}$-banking. Mobile banking mainly concerned the things of a transaction as well as financial services. In this paper, we discuss adaptation strategies and make an analysis of rural consumer behavior about mobile banking. Similarly, we discuss different mobile banking facilities and upcoming facilities which should be utilized by rural Indian people to connect rest of the world with efficiently. With that, we have a study, which factor play significant roles in rural India for deep penetration of mobile banking. As well as, study about his behavior and make an analysis of rural consumers for adaptation of beneficial technology and services to come out from a root and play at tip position in modern society. It is evident in recent time that mobile devices or handheld devices like PDA (Personal Digital Assistance) application are widespread due to its cost, ease of use, efficiency, and effectiveness. But optimum penetration exhibit inhibits by social misconception such as security and not maintain transparency before, during and after transactions.
\end{abstract}

Index Terms - Information technology, mobile banking, financial services, wireless communication means, handheld devices

\section{INTRODUCTION}

Information technology application is wide; we cannot bind it in a particular constraint. It acts as a small needle some places; however, on some place it acts as a gigantic sea tanker that needs to cross a big ocean. Mean, information technology is a modern society part to uplift from traditional services to automation services.

Furthermore, different types of communication media have been evolved as fast pace within a decade. Like $i$ - phones, PDA etc. Its functionalities also evolved with full pace, which is not expected earlier by consumers, marketers like the ease of use, computation power, and cost effectiveness. These are some features which have been attracted to decorate with a different application in it by mobile manufacturer. One feature among these is that mobile banking services and financial services. A mobile bank service is provided by a respective service provider which possess and access by users. Its application is wide and visible into urban users in large proportion, but its application is not an appreciable in the rural Indian users. Mobile banking is not much flourish in rural mobile users and for these have different reasons such as -

- Rural users are not aware of technological advancement as well as its services.

- Rural users having a misconception about security as well as password.

- Mobile banking services and its application not being the renaissance in great extent by government and policymakers.

Thousands of people from rural areas across 29 states are likely to get their social security pension and wages paid under the National Rural Employment Guarantee Act (NREGA) scheme with the help of mobiles over the coming few months.

In Andhra Pradesh alone, for instance, 250,000 people have registered for mobile banking services. The state government is rolling out a programme to enroll three million people by the end of 2008. Mobile banking pilots and full-scale operations are being conducted across 12 states, and the entire ecosystem is being managed by the government with the help of the Reserve Bank of India, banks, leading telecom operators, and technology implementation partners.

The ecosystem is important since banking regulations in India currently do not allow cash for an exchange of another 'unit' such as 'airtime' in the case of mobiles. Only banks and the Indian Post (through money orders) are currently allowed such transfers. Mobile banking, which is catching up fast in the cities and hinterland, is not only helping the government to take a step forward towards 
fulfilling its aim of having one bank account for every household, but also saving it crores of rupees by way of reduced transaction costs.

While the government incurs a transaction cost of Rs 12-13 for every Rs 100 it sale out, mobile banking helps it reduce the cost to a mere Rs 2 . RBI estimates that around 40 per cent of Indians lack access to formal financial services and is largely 'unbanked'. For instance, the AP government has tied up with banks like the State Bank of India, Union Bank of India, Axis Bank, Andhra Bank, State Bank of Hyderabad, Andhra Pradesh Grameen Vikas Bank, and Punjab National Bank.

A Little World (ALW), a technology implementation partner, has collaborated with NXP Semiconductors to design a mobile for the AP government that encloses a RFID card and works with ALW's micro-banking platform ZERO. The mobile acts as a branch of the bank by storing a database of customers. It also has a smartcard, which biometrically stores the identity of the customer such as name, address, photograph, fingerprint templates and relevant details of the savings or loan accounts held by the issuing bank.

Customers get a secure electronic identity via phone or smartcard, while agents take deposits and dispense cash. ALW works with the banks on a revenue-sharing basis. Under this initiative, the cooperative department will provide mobile handsets to farmers at a marginal price through its outlets in the rural areas. These handsets would be loaded with green SIM cards, which will flash daily updates on agricultural practices and weather forecast free of cost. In this note, discuss the rural consumer behavior for adaptation of mobile banking for their transactions as well as financial services.

India is a developing country and mobile users exponentially increase day by day. Therefore, it is prevalent to access every service that has available in mobile devices. In fact, keeping a view of its functionalities and user-friendliness, most of the rural consumers can use this device for completion of their daily transactions instead of a rush towards the banks for completion of their miscellaneous works. By application of this device for m-banking, we can reduce poverty somewhat extents by knowing local and central government plans for rural peoples [1][2]. Different hurdle has existed for access the m-banking by a rural person due to his illiteracy or semi-literacy in particular of India. With that, lack of renaissance by the government is significantly responsible for it. The government should need to adapt as such strategies and make the plan by which Indian rural peoples can build confidence over mbanking [3][4][5].

For building trust on m-banking, not only the government but local and respective geographical conditions also play a significant role. For adaptation of this mechanism in perspective of India different adaptation policies should be built by the every sector that is direct or indirectly attached with this mechanism. By them, Indian rural people make confidence on financial and others transaction by mobile. Step by step build confidence and spread his success story among surround environment. On such way, we could make a plan for adaptation of m-banking by Indian rural consumers [6][7][8][9][10].

An adaptation of this phenomena is nor easier as we look at the first phase. It is layered process which depends on one another. Initial layers are challenging but subsequent layers depend on the predecessor, hence, predecessor layers are not so complicated for implementation in Indian rural areas. In perspective of Indian context, enormous challenges existing in recent time and lots of challenges will raise in future once it will implement for rural peoples. A few challenges listed in below as perspective of Indian rural geographical condition [11][12][13][14][15] -

- Every Indian village is not connected to the internet. Lack of internet connection unavailability in Indian villages.

- The speed of internet is very slow in particular of villages.

- The apathy of Government.

- Misconception in rural people about m-banking.

- Inappreciable government strategies about mbanking as well as uses of digital devices for banking transactions and much more.

Let we look all these in this research paper in the context of Indian consumers as well as its rural consumers.

\section{RELATED WORK}

In recent times, mobile devices use the common person since its success factor is the convenience, ease of use, ubiquity, and trust [16]. Mobile devices possess different application, lots of apps and cost-effective due to that, mobile commerce is widespread. Mobile commerce found in academic literature, MIS, management, and marketing, all have various approaches to define as to what exactly constitutes mobile commerce.

Current mobile Internet applications enable customers to gain access a variety of services: Web Information search, SMS (Short Message Service), MMS (Multimedia Message Service), banking, payments, gaming, emailing, chat, weather forecast, GPS (Global Positioning Service) etc, all of these services included into the mobile commerce(m-commerce) [17].

Mobile service applications are highly depending upon human behavior and its technical skills. Technical skill is directly dependent on practical usage of electronic equipment. Predicting consumer behavior is uncertain and it is geographical sphere [18].

A planned behavior [19], derived from TRA, which also studies the human behavior. This model has also been used to study the adaptation pattern of mobile commerce service [20]. The [21] designed technological acceptance models of four organizations, two usages voluntary whereas rest of two involved for mandatory for models and make an analysis on them for usage of technology. Furthermore, [22] has focused on m- 
commerce with a perspective of markets and consumers. Similarly, research papers [23][24][25] emphasis on mcommerce by usage technology, challenges, future implication, user perspective regarding usage etc.

The [23] make a comparative analysis on m-commerce and e-commerce. Furthermore, for clear understanding, it has mentioned supporting technologies which are a need for e-commerce as well as m-commerce. Subsequently, m-commerce used different technologies such as wireless networks, wireless protocols, and wireless devices for transfer product details from one place to another place without any geographical and geopolitical constraints. The mobile internet users were $25 \%$ in 2000 and it is subsequently growing more rapidly even in developing country such as India. To offer reliable internet services to potential customers, it needs to more secure, reliable, download images and its contents within a fraction of the time, and internet cost should be low which can be afforded by the common customers.

The [24] has defined four categories for handheld device adaptations. The four categories are talkers, writers, photographers, and surfers. By talkers, we have to provide voice services to handheld device users. On other hands, writer particularly used the SMS services for product marketing to reach common handheld users. The photographers play the significant roles for mobile services adaptations. In this MMS and camera photographs are used for m-commerce. An addition of MMS and camera photographs we can add voices and textual content for enhancement of e-commerce adaptation among common customers. Finally, surfers used the GPRS for adaptation of handheld devices.

Thus, India is emerging country concerned of information technology and uses. Recent time Indian government has been launch different types of digital policy such as Make in India, Digital India and so on. Similarly, Indian government makes efforts to promote cashless transactions in every sphere and its efforts vividly visible across the India. Nowadays, most of the Indian consumers has been used the handheld devices for completion of their daily needs. Among these daily needs, mobile banking is one of the entities.

\section{OBJECTIVE(S) OF RESEARCH}

Regulations in the have been relaxed but the adaptation of mobile banking services in rural India is still held back by various challenges including low-value transactions, lack of focus from banks, financial illiteracy and facility of cash-points.

The statistics indicate much potential in India mobile banking market. The country is home to the secondlargest mobile phone population of over 600 million subscribers, at a penetration rate of 57 percent. At the same time, nearly 40 percent of the Indian population remains unbanked. And of those who are banked, a large chunk is under-banked.

A majority of the unbanked population resides in rural India, where the penetration of mobile telephony is 31 percent and growing at a fast clip. And estimated 8 million rural Indians who own mobile phones do not have access to banks.

Today, there are various mobile banking services including mobile-to-mobile transactions and remote ATMs. Most of those applications are cost-effective but it is the volume of transactions that makes mobile banking unviable for banks.

To address the unbanked population in rural access, banks have partnered business correspondent that have the reach and low-cost technology tools to ensure feasibility. But while this has lead to same growth in mobile banking services the percentage is negligible.

Enrolling users for mobile banking services can also be a painstaking process, and on top that, money disbursed and the Mahatma Gandhi National Rural Employment Guarantee Act (NREGA) can be as little as US\$2.15 (INR 100) per person, per month. Such small transactions do not make it viable for banks to go the whole hog with their mobile banking plans.

\section{METHODOLOGY}

Rural consumer behavior complexities for adaptation of mobile banking are depending on the cognitive and psychomotor analysis. Hence, for this, it is useful to collection different research articles, reports and research papers related to the mobile banking. There are different models available for technology acceptance, and researchers apply different models for measurement of human behavior parameters like Technology Acceptance Model (TAM), Theory of Panned Behavior (TPB) and Innovative Diffusion Theory (IDT) etc. these models is useful for analysis of $\mathrm{m}$-banking services perspective to Indian rural consumers.

The addition of above-mentioned parameters, we collect primary data by taking feedback, questionnaire, and rural mobile user consumer on-site meeting and metrics rural customers cognitive for hurdle of technology acceptance lay adaptation of mobile banking. For it, draw ten questions and getting feedback through face-to-face in the Indian rural villages. The list of questions such as -

1. How many persons possess hand-held devices like PDA (Personal Digital Assistance), mobile phone etc in the villages?

2. Know about mobile banking and financial services?

3. If use m-banking, then any difficulties encountered by them?

4. There exist any misconceptions regarding mbanking. If it is so, what these misconceptions?

5. Knowledge about different services which provided by a bank through electronic devices such as a mobile bank?

The tabular form representation of analyzed data of the above such as - 
Table. 1. Application of Mobile by Indian Users and Face Difficulties on Application of It

\begin{tabular}{|c|c|}
\hline Particulars & $\%$ age of use \\
\hline Mobile users in Indian Rural People & $80 \%$ \\
\hline $\begin{array}{c}\text { Knowledge about m-banking and its different } \\
\text { services }\end{array}$ & $10 \%$ \\
\hline Difficulty to use mobile banking & $80 \%$ \\
\hline m-banking application misconceptions & $90 \%$ \\
\hline Benefits of m-banking & $10 \%$ \\
\hline
\end{tabular}

\section{ROLE OF M-BANKING FOR INDIAN RURAL CONSUMERS}

The following roles are significantly play if traditional banks services transforms as in m-banking services -

- It is cost effective and easy to use services.

- It is an efficient and effective medium for access various banking services.

- Need minimum requirement of physical infrastructures.

- There is no need to set bank as physical on every of a corner of a particular location.

- Minimum requirements of human resources for fulfillment of consumer requirements.

- Less workload on bank employees.

- Promote towards of paperless transaction services.

The following few points are significant in perspective of Indian rural consumers-

- Make global reach.

- Make update banks plans that occur frequently.

- Easy to know government different policies by Indian rural consumers on time.

- Make independent somewhat extents.

\section{ADAPTION STRATEGIES}

A few adaptation strategies are listed as follows by which Indian rural consumer fees confidence on $\mathrm{m}$ banking system-

- There is inappreciable internet facility available across the whole rural India due to this consequence m-banking are not well-known by Indian rural consumer.

- Another hurdle for adaptation of this mechanism by the rural Indian consumer is that its complexity. Due to its complexity, rural common people frequently avoid this mechanism for access for completion of their daily transactions.

- Lack of compatibility with rural consumers is also a major point by which adaptation of it creates problems among Indian rural peoples.
- Show a lack of interest in m-banking by rural peoples.

- Lack of knowledge regarding the internet, recent technology, computerized banking different services.

- Use of the internet is much expensive by which creates problems for adaptation of this mechanism.

- Internet connection speed is inappreciable so that most of the rural people avoid using this mechanism.

- The government needs to make the plan for attracting rural people towards m-banking like Digital India launch by the Indian government to attract masses of peoples towards a digital system for completion of their daily needs.

\section{Challenges}

A few points listed below which are more significant challenges for implementation of m-banking system in every corner of India-

- Internet security and risk are not up to mark. Consequences of this, most of the Indian consumers avoid it for financial transactions and sharing of confidential information from one point to another point.

- Indian geographical condition is not same on every corner of India that is big challenges to ISP and Indian government policymakers.

- High-speed internet not available in rural areas.

- The cost of internet connection by rural peoples not affordable.

- Make additional charges by the bank on using of m-banking different services.

\section{MAJOR FINDING}

From above data collection, there is more interesting fact collected regarding an application of m-banking in rural area perspective to the Indian people. Most of the rural people do not know about m-banking and different facilities. They preferred to transaction all financial matters through a physical bank. They consider, it is safest and convenient to use and user-friendly instead of bank resources located miles of away from them. The knowledge about mobile banking and its services for rural people is not so much appreciable as per diagram is shown in fig. 1.

Fig. 2 indicates that m-banking main hurdle in Indian rural areas is technology illiteracy $(77 \%)$, lack of internet facility through wireless or broadband by a particular service provider, its percentage is $88 \%$. Internet bandwidth is not appreciable in rural areas as compared to the urban areas. Among these, most problematic of that, lack of knowledge of hand-held devices and its available functionalities. 


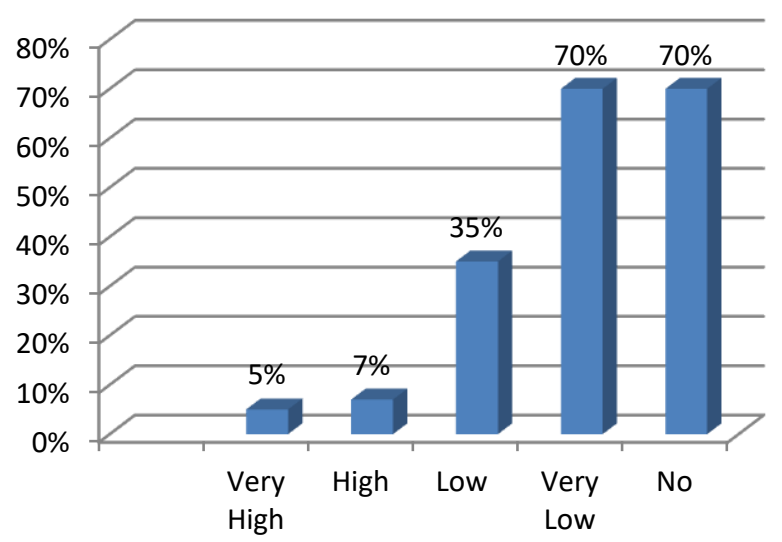

Fig.1. M-banking knowledge among Indian rural consumers

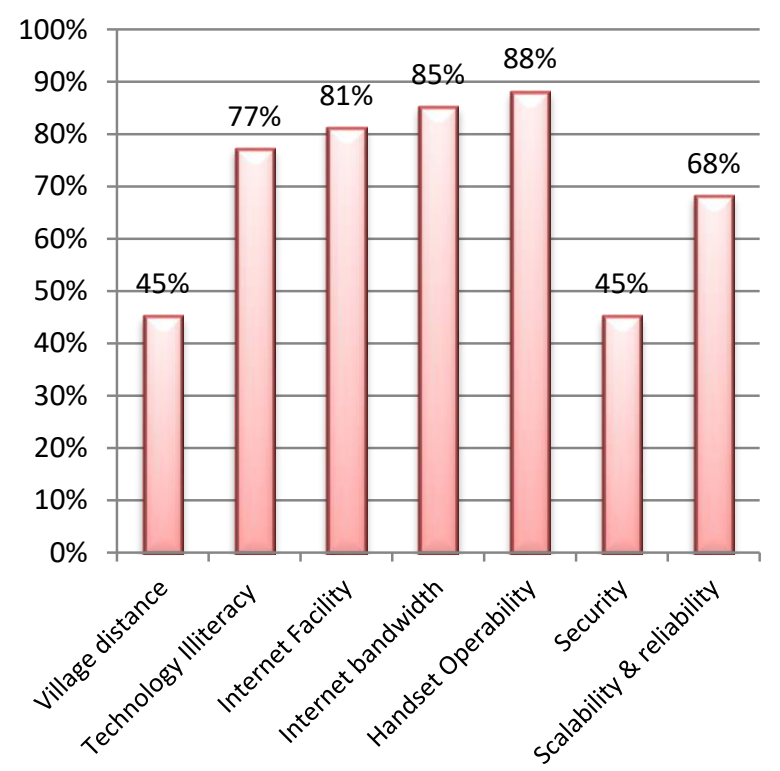

Fig.2. Difficulties to use mobile banking and its services by Indian rural consumers

In fig. 3 indicate that, different types of facilities provided by the bank. Among different digital facilities, common facilities are fund transfer, bill payments, balance inquiry, ticket booking and current account information. These facilities utilization full extent in urban part but in rural part is not much appreciable; in the information technology age.

The m-banking system use by a male is very high comparatively of female consumer in Indian rural area (fig. 4). The reason of this is that most of the Indian rural female consumers are illiterate as well as dependent on others.

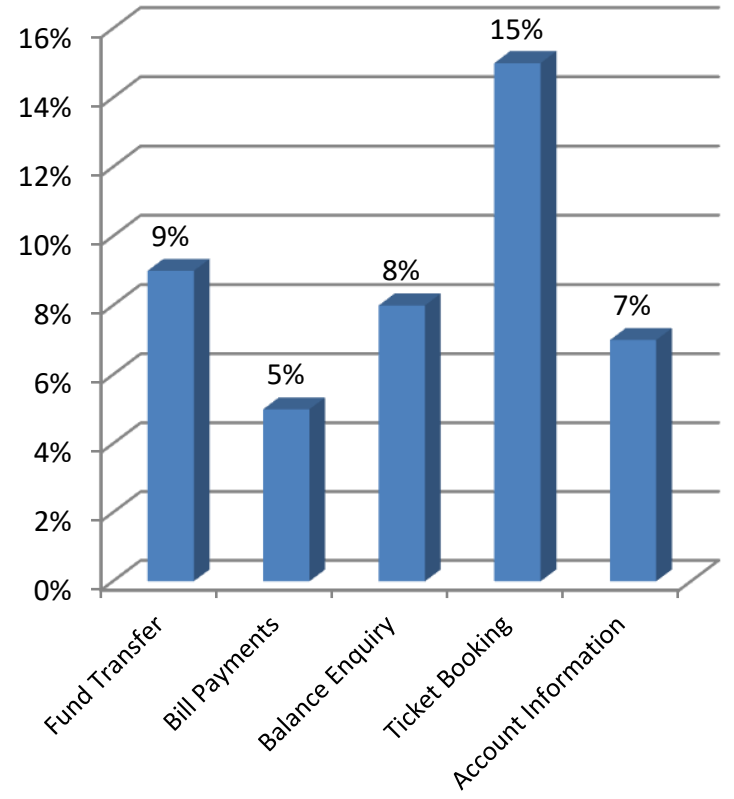

Fig.3. Knowledge about m-banking services among Indian rural consumers

m-banking access by Indian rural consumers

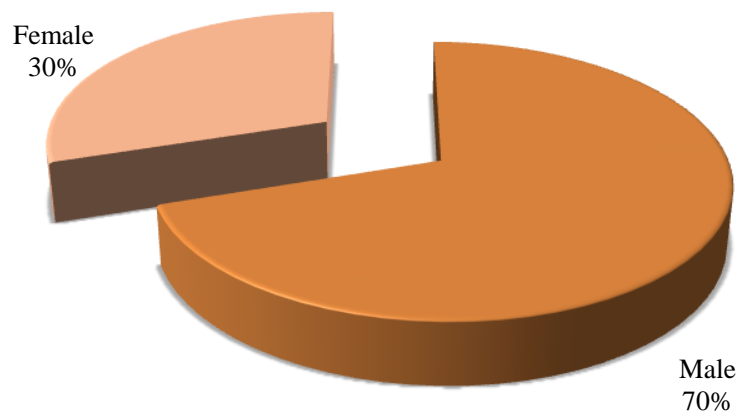

Fig.4. Proportions of m-banking system access by Indian rural consumer

In India different types of local, national and international language used for daily conversation. However, the national and international language widely use in urban areas whereas in rural areas their local or regional languages being widely used for conversation. Hence, it is essential to promote local or regional languages in the m-banking system. Similarly, content should not be in complex forms by which rural seems awkward about this mechanism. M-banking site contents should simple, concise and user-friendly. The Table 2 and fig. 5 demonstrates about this. 
Table.2. Language Preference Survey for M-Banking Site

\begin{tabular}{|c|c|c|c|c|}
\hline & \multicolumn{4}{|c|}{ Language } \\
\hline $\begin{array}{c}\text { Age } \\
\text { Group }\end{array}$ & Local & Regional & National & International \\
\hline $10-20$ & 5 & 15 & 30 & 50 \\
\hline $21-30$ & 4 & 26 & 20 & 50 \\
\hline $31-40$ & 2 & 35 & 35 & 28 \\
\hline $41-50$ & 6 & 50 & 20 & 24 \\
\hline $51-60$ & 8 & 60 & 15 & 17 \\
\hline $61-70$ & 10 & 65 & 15 & 10 \\
\hline
\end{tabular}

- Local $\square$ Regional National $\square$ International

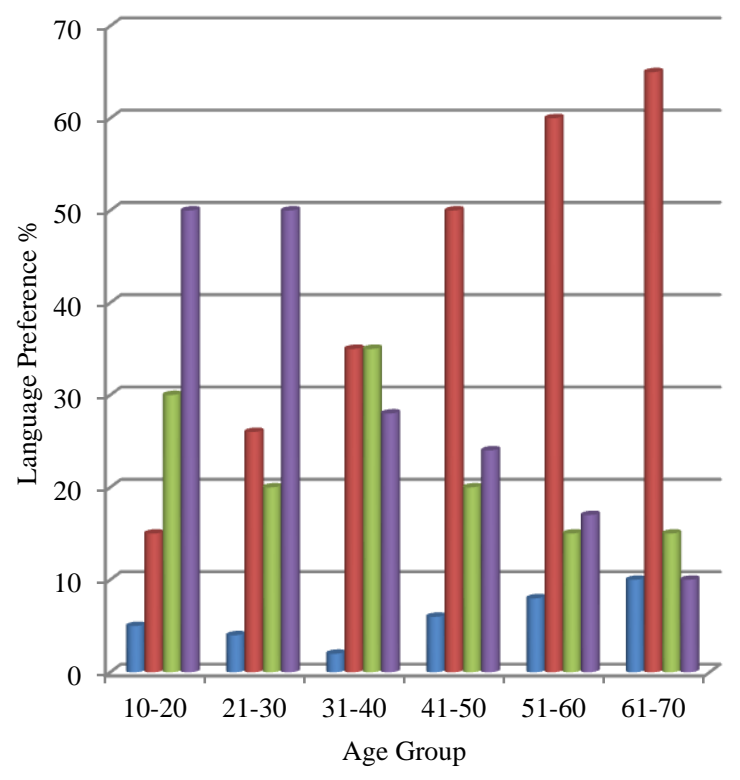

Fig.5. Language preference survey for design m-bank app for mobile devices

We have been collected data from Indian urban consumers and rural consumers when they start of $\mathrm{m}$ banking for transactions. We had to take different rural people's samples keeping in view of state literacy rates, geopolitical ground, technological availability, internet connection on their location, state as well as central government schemes regarding the m-banking transaction. We collected data from 20 Indian villages and 20 urban areas. Fig. 6 indicates that after launching of Digital India, Making in India, and Online Transactions campaign in 2015-16, most of the rural population access the mbanking for completion of their daily transactions. Similarly, when we survey about m-banking hurdle for adaptation of this mechanism then we found that most of the rural areas have not internet connection. If an internet connection available in rural areas then its speed is not in an appreciable form.

\section{Application of $m$-banking in Indian rural vs. urban consumers}
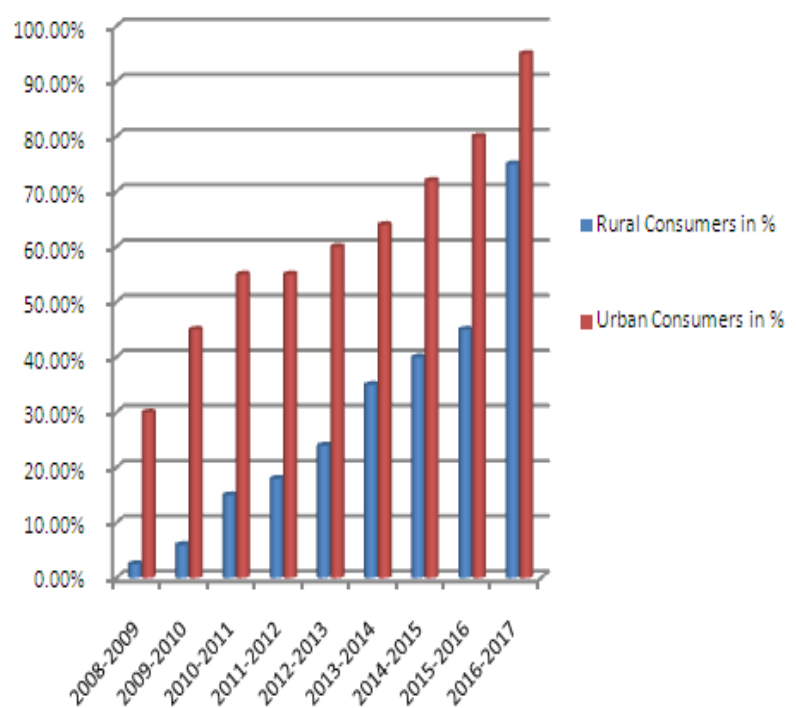

Fig.6. Application of m-banking in Indian Rural people as well as urban Indian people from 2008-2009 to 2016-2017

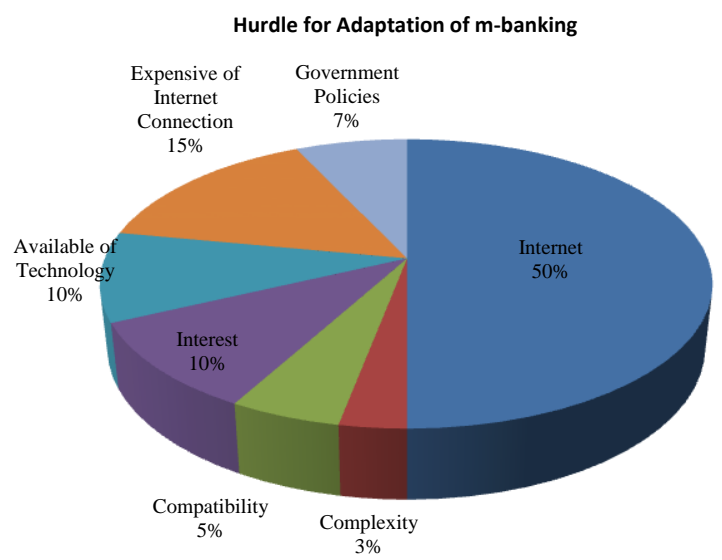

Fig.7. Barriers for adaptation of $\mathrm{m}$-banking in Indian rural consumers

\section{CONCLUSION}

India is a developing country due to that fundamental technological advancement for society modernization is not appreciable as compared to developed nations. But, in India, mobile penetration is high due to its costeffectiveness of mobile devices. By mobile phone, basic services utilization will go to high such as mobile banking.

In recent times, every bank provides services on the mobile phone, but it has not captured the general public attention. Technological advancement going rapid pace especially in the mobile devices like improved display, memory size, processing speed etc by which any type operations perform in quickly from anywhere, anytime.

In this paper, we discussed rural Indian mobile consumers regarding mobile banking and his/her 
difficulties for operating mobile devices. The main hurdle of mobile banking in rural population is that availability of resources like ATMs, online banking etc, but it is also in limited areas in rural. The main hurdle of mobilebanking in Indian rural population is that technology illiteracy, a misconception regarding safety and security, lack of awareness of mobile banking etc. The availability of alternate channels is few in rural India compare to the urban India. The mobile phone usage is good in rural India so banks can easily reach to rural population with the help of mobile banking.

\section{REFERENCES}

[1] Bhavnani, A., Chiu, R. W. W., Janakiram, S., Silarszky, P., \& Bhatia, D. (2008). The role of mobile phones in sustainable rural poverty reduction. retrieved November, $22,2008$.

[2] Aker, Jenny C., and Isaac M. Mbiti. "Mobile phones and economic development in Africa." The Journal of Economic Perspectives 24.3 (2010): 207-232.

[3] Ram, Sundaresan, and Jagdish N. Sheth. "Consumer resistance to innovations: the marketing problem and its solutions." Journal of Consumer Marketing 6.2 (1989): 514.

[4] Mukherjee, Avinandan, and Prithwiraj Nath. "A model of trust in online relationship banking." International journal of bank marketing 21.1 (2003): 5-15.

[5] Safeena, Rahmath, et al. "Technology adoption and Indian consumers: study on mobile banking." International Journal of Computer Theory and Engineering 4.6 (2012): 1020 .

[6] Mols, Niels Peter. "The Internet and the banks' strategic distribution channel decisions." International Journal of Bank Marketing (2013).

[7] Mallat, Niina, Matti Rossi, and Virpi Kristiina Tuunainen. "Mobile banking services." Communications of the ACM 47.5 (2004): 42-46.

[8] Zhou, Tao. "An empirical examination of initial trust in mobile banking." Internet Research 21.5 (2011): 527-540.

[9] Tiwari, Rajnish, and Stephan Buse. The mobile commerce prospects: A strategic analysis of opportunities in the banking sector. 2007.

[10] Koenig-Lewis, Nicole, Adrian Palmer, and Alexander Moll. "Predicting young consumers' take up of mobile banking services." International journal of bank marketing 28.5 (2010): 410-432.

[11] Koenig-Lewis, Nicole, Adrian Palmer, and Alexander Moll. "Predicting young consumers' take up of mobile banking services." International journal of bank marketing 28.5 (2010): 410-432.

[12] Donner, Jonathan, and Camilo Andres Tellez. "Mobile banking and economic development: Linking adoption, impact, and use." Asian journal of communication 18.4 (2008): 318-332.

[13] Al-Jabri, Ibrahim M., and M. Sadiq Sohail. "Mobile banking adoption: Application of diffusion of innovation theory." (2012).

[14] Goi, Chai Lee. "E-Banking in Malaysia: Opportunity and challenges." The Journal of Internet Banking and Commerce 10.3 (1970): 1-11.
[15] Lin, Hsiu-Fen. "An empirical investigation of mobile banking adoption: The effect of innovation attributes and knowledge-based trust." International journal of information management 31.3 (2011): 252-260.

[16] Xu, Gordon, and Jairo A. Gutiérrez. "An Exploratory Study of "Killer Applications" and Critical Success Factors in M-Commerce." Web Technologies for Commerce and Services Online 231 (2007).

[17] Okazaki, Shintaro. "New perspectives on m-commerce research." Journal of Electronic Commerce Research 6.3 (2005): 160.

[18] Wang, Yi-Shun, Hsin-Hui Lin, and Pin Luarn. "Predicting consumer intention to use mobile service." Information systems journal 16.2 (2006): 157-179.

[19] Ajzen, Icek. "The theory of planned behavior." Organizational behavior and human decision processes 50.2 (1991): 179-211.

[20] Khalifa, Mohamed, and Kathy Ning Shen. "Drivers for transactional B2C m-commerce adoption: Extended theory of planned behavior." Journal of Computer Information Systems 48.3 (2008): 111-117.

[21] Venkatesh, Viswanath, and Fred D. Davis. "A theoretical extension of the technology acceptance model: Four longitudinal field studies." Management science 46.2 (2000): 186-204.

[22] Balasubramanian, Sridhar, Robert A. Peterson, and Sirkka L. Jarvenpaa. "Exploring the implications of m-commerce for markets and marketing." Journal of the academy of Marketing Science 30.4 (2002): 348.

[23] Coursaris, Constantions, and Khaled Hassanein. "Understanding m-commerce: a consumer-centric model." Quarterly journal of electronic commerce 3 (2002): 247272.

[24] Constantiou, Ioanna D., Jan Damsgaard, and Lars Knutsen. "The four incremental steps toward advanced mobile service adoption." Communications of the ACM 50.6 (2007): 51-55.

[25] Davis, Fred D. "Perceived usefulness, perceived ease of use, and user acceptance of information technology." MIS quarterly (1989): 319-340.

\section{Authors' Profiles}

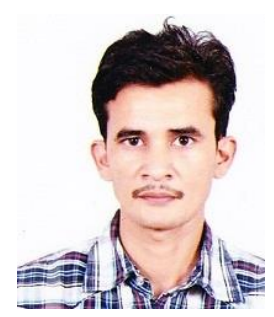

Shyam R. Sihare is the Ph. D. candidate in Raksha Shakti University, Ahmedabad, India. He took up his Master's degree in Computer Science at Nagpur University, Nagpur, India in 2003 and obtained M. Phil. in Computer Science at Madurai Kamraj University, Madurai, India. He cleared Professor Eligibility Test GSLET, Gujarat, India in 2011. He obtained MCA at IGNOU, New Delhi, India in 2011.

$\mathrm{He}$ is currently working as Asstt. Professor in Computer Science and Application in Dr. APJ Abdul Kalam Govt. College, Silvassa, Dadra \& Nagar Haveli(UT), India. His research interests include Quantum Computer, Quantum Algorithms, Quantum Cryptography, and Classical Computer Algorithms. 
How to cite this paper: Shyam R. Sihare, Abdullah Ahmad Basuhail," Role of m-Banking for Indian Rural Consumers, its Adaptation Strategies, and Challenges: Consumer Behavior Analysis", International Journal of Information Engineering and Electronic Business(IJIEEB), Vol.9, No.6, pp. 35-42, 2017. DOI: 10.5815/ijieeb.2017.06.05 